Research Article

\title{
Effect of Biowaste on the High- and Low-Temperature Rheological Properties of Asphalt Binders
}

\author{
Xuancang Wang, ${ }^{1}$ Yuchen Guo $\triangle{ }^{1},{ }^{1}$ Guanyu Ji, ${ }^{1}$ Yi Zhang, ${ }^{1}$ Jing Zhao, ${ }^{1}$ and Hao Su ${ }^{2}$ \\ ${ }^{1}$ School of Highway, Changan University, Xi'an 710064, China \\ ${ }^{2}$ School of Civil Engineering, Xi'an University of Architecture and Technology, Xi'an 710061, China \\ Correspondence should be addressed to Yuchen Guo; 15229242490@163.com
}

Received 13 February 2021; Revised 14 April 2021; Accepted 4 May 2021; Published 18 May 2021

Academic Editor: Hui Yao

Copyright (C) 2021 Xuancang Wang et al. This is an open access article distributed under the Creative Commons Attribution License, which permits unrestricted use, distribution, and reproduction in any medium, provided the original work is properly cited.

\begin{abstract}
The growth of aquaculture has increased the production of oysters. However, the increased oyster shell volume has created serious environmental and recycling problems for the society. In order to study the sustainable utilization of waste oyster shells, asphalt binder of waste oyster shell powder was prepared by using modified asphalt material with waste oyster shells. The microstructure of oyster shell powder was analyzed by scanning electron microscopy experiments. The chemical composition of the asphalt binder was observed by Fourier transform infrared spectroscopy tests. The physical properties of the asphalt binder, including softness, high-temperature performance, and plastic deformation capacity, were initially evaluated through three indicators' tests on asphalt. A preliminary performance evaluation of the asphalt binder was performed. The high-temperature stability of asphalt binders was evaluated using dynamic shear rheometry. The rutting resistance of the material was evaluated by temperature sweep tests, and the shear deformation resistance of the material was evaluated by frequency sweep tests. Multiple stress creep recovery tests determine the material's ability to resist permanent deformation. The low-temperature rheological properties were evaluated by bending beam rheology tests. The study found that the waste oyster shell powder is a biomass with a porous irregular petal shape. No new characteristic absorption peaks are formed by mixing with asphalt. And, it can improve the viscosity, thermal stability, and temperature-sensitive properties of the material. It significantly improved the high-temperature rheological performance, rutting coefficient, and recovery elasticity of the material. However, it has little effect on low-temperature rheological performance. This study provides a solid foundation for the effective use of biowaste in engineering materials.
\end{abstract}

\section{Introduction}

Economic development and increasing consumption levels have led to a yearly increase in the global generation of municipal domestic waste $[1,2]$. Due to its high water content and perishable nature, this waste can damage the ecological environment. However, it also contains a large amount of biomass energy, which is a valuable renewable resource $[3,4]$. Currently, oyster products are widely distributed and have high organic component content. Many oyster shells are discarded during processing and consumption without effective exploitation, and they have become a serious source of pollution [5]. In some areas, a flood of oysters can also pollute the marine ecosystem, as in the case of the Pacific oysters that swept the beaches along the west coast of Denmark in 2017, severely damaging the local marine ecosystem [6]. Therefore, a reasonable utilization of oyster shell waste is one of the current research problems. In the biomedical field, competitive inhibitors against the angiotensin-converting enzyme have been developed by isolating functional peptides from oyster shell hydrolysis products [7]. It was found that the oyster shell powder and dicalcium phosphate dibasic dihydrate can produce hydroxyapatite under ball-milling and high-temperature calcination conditions [8]. In the field of biomedicine, oyster shells have been used for the development of anti-ACE competitive inhibitors [9]. In the field of environmental science, oyster shells have been used for marine environment 
remediation [10] and improvement of acidic sulfate soils [11]. In the field of food science, oyster shells can be used to make preservatives [12] and additives for food products [13]. However, there is still a large amount of oyster waste being buried [14], which not only negatively affects human health [15] but also increases the cost of waste disposal [16] and harms economic development. Therefore, it is crucial to develop a new method for disposal of this waste.

The utilization of shellfish products in the field of engineering materials has been extensively studied. However, most of the researches have focused on the incorporation of bio-shell waste into cement-based materials, but less research was about that used by asphalt modification. The high $\mathrm{CaCO}_{3}$ content in the shells can be used to produce cement. The use of shells instead of the coarse or fine aggregates in concrete decreases their work performance, but the compressive strength of the material increases when the coarse aggregate replacement rate is less than $25 \%$ or the fine aggregate replacement rate is less than $10 \%$ [17]. The basic properties of self-compacting mortar with shells as fine aggregate are not affected; when the shell replacement rate reaches $100 \%$, the mortar has better flowability [18]. Asphalt concrete is widely used in high-grade highways, urban roads, and bridge deck pavements with good serviceability and comfort, and is the main engineering material in infrastructure $[19,20]$. However, petroleum asphalt, as a nonrenewable energy source, inevitably limits the development of road construction [21]. Therefore, bio-asphalt, as a new renewable paving material, has become an active topic of research in the engineering field [22, 23]. To date, waste cooking oil and waste vegetable oil are the most common bio-oil-modified materials [24]. There are also modified asphalt binders that use animal manure as an additive $[25,26]$. Vegetable oil can soften asphalt and improve lowtemperature performance. However, pig manure bio-oil not only decreases the viscosity of asphalt binders but also enhances their thermal cracking properties [27, 28]. The use of lignin powder and lignin-fiber-modified materials can enhance the physical properties of asphalt [29]. Corn-stalkmodified materials will improve the temperature sensitivity of the material [30]. The wood bio-oil asphalt binder meets all specifications and can be used for road paving [31]. Dynamic simulation of the diffusion mechanism and rheological properties of asphalt recycled from waste wood biooil, with enhanced extension and elasticity compared to asphaltene, saturated oil and resin [32, 33]. The high-temperature rheological properties of the waste crayfish asphalt binder were substantially improved [34].

To sum up, bio-asphalt has a great potential in the field of sustainable pavement materials, but it must be modified to address the problem of decline in the performance of asphalt and asphalt mixtures and enhance its applicability in highway engineering construction. On this basis, this study analyzed the microstructure of oyster shells and evaluated the effect on asphalt properties produced by its use as a modified material. The new idea of using oyster shells as biological waste to improve the asphalt performance is put forward, and a bridge between crustacean organic waste and asphalt materials is established, which can solve the problems of environmental pollution and waste of resources. This study contributes to the sustainable development of highway engineering by using bio-renewable materials, and it is a guide to promote the application of bio-asphalt in asphalt pavements.

The remainder of this paper is structured as follows: Section 2 focuses on the asphalt type and the microstructure of oyster shell powder. The chemical composition of asphalt binder, the three indicators, and the rheological properties of the test methods are introduced in Section 3. Section 4 provides a detailed analysis of the properties of the asphalt binder based on the test results and a comparative analysis with the research results of other researchers. Finally, in Section 5 , the conclusion is summarized.

\section{Materials}

2.1. Asphalt. Karamay (KLMY) AH-70\# asphalt, the most common asphalt pavement raw material in Shaanxi, was selected. The matrix asphalt index is listed in Table 1.

The waste oyster shells were obtained from Xi'an. After being washed with clean water, they were dried in the oven for $12 \mathrm{~h}$ at $90^{\circ} \mathrm{C}$. Oyster shell powder particles less than $0.15 \mathrm{~mm}$ is size were denoted as OS, as shown in Figure 1 .

\subsection{Microstructure of Oyster Shell Powder. A SEM (S-4800)} produced by Hitachi was used to observe the distribution and morphological characteristics of the shell powder, which was beneficial for understanding the microstructural characteristics of the waste oyster shell powder and exploring its influence on asphalt materials. SEM images at different magnifications of the oyster shell powder are shown in Figure 2.

The oyster shell powder biological filler is composed of an inorganic aragonite layer and organic matter. The inorganic aragonite layer is composed of aragonite flakes parallel to the shell surface, and each aragonite flake is composed of nano aragonite fibers. As shown in Figure 2, the powder has an irregular block structure with sharp edges and corners, and it shows angularity. There are many holes in the block structure, which can provide adsorption sites for asphalt, and this indicates that the structure of oyster shell powder is beneficial for absorbing more asphalt. As shown in Figure 2(d), the structure of oyster shell powder is clustered and stacked in a petal pattern, which is accompanied by a small number of pores. This structure leads to tighter mixing of the particles with asphalt, which changes the various properties of the asphalt.

\section{Methods}

3.1. Research Methodology Flow Chart. The flow of the research methodology in this paper is shown in Figure 3.

3.2. Preparation of Studies Materials. High-speed shear (FM300) manufactured by Shanghai Fluke Liquid Machinery Manufacturing Company was used for the studied materials. The waste oyster shell asphalt binder material was 
TABle 1: Performance parameters of AH-70 asphalt.

\begin{tabular}{lccc}
\hline Performance & & JTG E20-2011 & \\
& Test results & Requirements & Test method \\
\hline Penetration $\left(25^{\circ} \mathrm{C}, 100 \mathrm{~g}, 5 \mathrm{~s}\right)(0.1 \mathrm{~mm})$ & 66.5 & $60-80$ & $\mathrm{~T} 0604$ \\
Softening point $\left({ }^{\circ} \mathrm{C}\right)$ & 50.5 & -46 & $\mathrm{~T} \mathrm{0606}$ \\
Extension $\left(5^{\circ} \mathrm{C}, 5 \mathrm{~cm} / \mathrm{min}\right)(\mathrm{mm})$ & 78 & $\geq 180$ & $\mathrm{~T} 0605$ \\
Dynamic viscosity at $60^{\circ} \mathrm{C}(\mathrm{Pa} \mathrm{s})$ & 260 & $\geq 260$ & $\mathrm{~T} 0620$ \\
Flash point $\left({ }^{\circ} \mathrm{C}\right)$ & $>300$ & $\leq 2.2$ & $\mathrm{~T} 0611$ \\
Paraffin wax content $(\%)$ & 1.74 & Actual test records & $\mathrm{T} 0615$ \\
Density $\left(25^{\circ} \mathrm{C}\right)\left(\mathrm{g} \cdot \mathrm{cm}^{-3}\right)$ & 0.979 & $\mathrm{~T} 0603$ \\
\hline
\end{tabular}

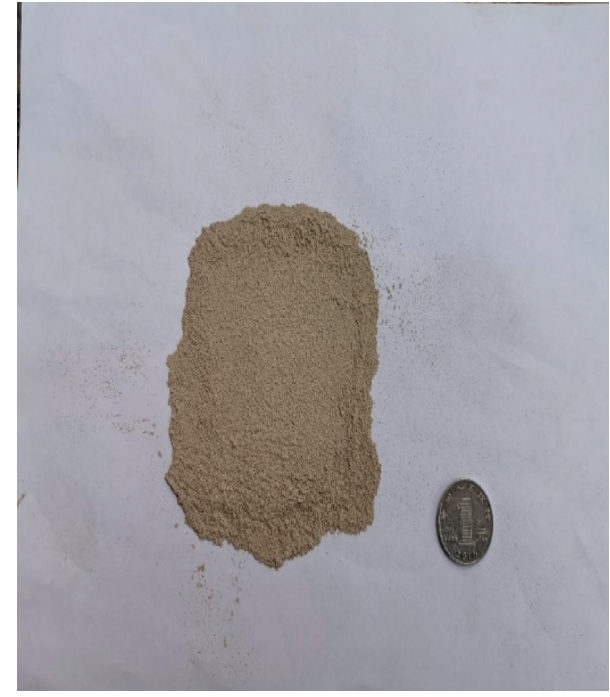

FIgURE 1: Waste oyster shell powder.

produced by the following method: set the oven temperature at $135^{\circ} \mathrm{C}$, heat $\mathrm{AH}-70$ asphalt for $1 \mathrm{~h}$, and then pour into a container. The temperature was maintained at $150 \pm 5^{\circ} \mathrm{C}$ by the electric furnace control. Add waste oyster shell powder modified by three different proportions (5\%,10\%, 15\%). First, manual mixing was performed for $10 \mathrm{~min}$, followed by pre-mixing for $10 \mathrm{~min}$ at $2000 \mathrm{rpm}$, and finally mixing for $30 \mathrm{~min}$ at $3000 \mathrm{rpm}$.

3.3. Fourier Transform Infrared (FTIR) Spectroscopy Test. FTIR tests were performed using a TENSOR II Fourier transform infrared spectrometer (BRUKER, Germany). The test spectral range was $400-4000 \mathrm{~cm}^{-1}$.

3.4. Conventional Performance. Three indicators of asphalt binder were tested according to Chinese standard (JTG E202011) [35], that is, penetration test temperature of $25^{\circ} \mathrm{C}$, load of $100 \mathrm{~g}$, and penetration time of $5 \mathrm{~s}$. The ductility test was conducted at $5^{\circ} \mathrm{C}$. The softening point test was conducted using a water bath heating method. Furthermore, the physical properties of the waste oyster shell powder asphalt binder were evaluated.

3.5. Dynamic Shear Rheometer (DSR). DSR applies periodic stresses or strains to asphalt specimens by means of an oscillatory modulus to obtain material responses under frequency, temperature, and time scales [36], revealing the viscoelastic properties of asphalt binders [37]. The temperature sweep test, frequency sweep test reference JTG E202011 [35], and multiple stress creep recovery (MSCR) test reference AASHTO T 350-18 [38] were conducted using a $\mathrm{DHR}^{-1}$ hybrid rheometer (TA, USA).

3.5.1. Temperature Sweep Test. In this study, using the strain control mode, the strain was set to $1.5 \%$, and the asphalt specimen was sandwiched between two parallel plates. The temperature range was $40^{\circ} \mathrm{C}-70^{\circ} \mathrm{C}$. The properties of the complex modulus $\left|\mathbf{G}^{*}\right|$ and phase angle $\delta$ of the asphalt samples were analyzed to evaluate the rheological properties of the materials at different temperatures.

3.5.2. Frequency Sweep Test. The temperatures of the frequency sweep test were $58^{\circ} \mathrm{C}-70^{\circ} \mathrm{C}$, and the $\left|\mathrm{G}^{*}\right|$ and $\delta$ values of the materials studied under nondestructive conditions were measured by applying a dynamic shear load with a low strain level of $1.5 \%$.

3.5.3. Multiple Stress Creep Recovery Test. The temperatures of the asphalt in the MSCR test were $58^{\circ} \mathrm{C}, 64^{\circ} \mathrm{C}$, and $70^{\circ} \mathrm{C}$. The stress control mode was adopted in this experiment, which included two stages: loading and unloading. The experimental process of the asphalt was applied at two stresses $(0.1$ and $3.2 \mathrm{kPa})$. The loading was applied for $1 \mathrm{~s}$ and unloading for $9 \mathrm{~s}$ at each cycle, and 30 cycles were repeated in total. Twenty cycles of $0.1 \mathrm{kPa}$ stress followed by 10 cycles of $3.2 \mathrm{kPa}$ stress. The creep and recovery tests were completed in a total of $300 \mathrm{~s}$. The deformation generated in the loading phase of the experiment was partially recovered in the unloading phase, and the unrecoverable deformation was accumulated in the next cycle, which could better simulate the repeated loading and unloading processes of different traffic loads. Therefore, this test can reflect the actual deformation recovery capability of the pavement.

The samples were conditioned by the first 10 cycles in the 20 cycles at $0.1 \mathrm{kPa}$ stress, so the test information was recorded for the last 20 cycles. The initial strain of the specimen is recorded as $\varepsilon_{c}$. The strain at the completion of the cycle ( $1 \mathrm{~s}$ after the start of each cycle) was recorded as $\varepsilon_{c}$. The adjusted strain at the end of loading was obtained through the equation $\varepsilon_{1}=\varepsilon_{c}-\varepsilon_{0}$. The strain at the 


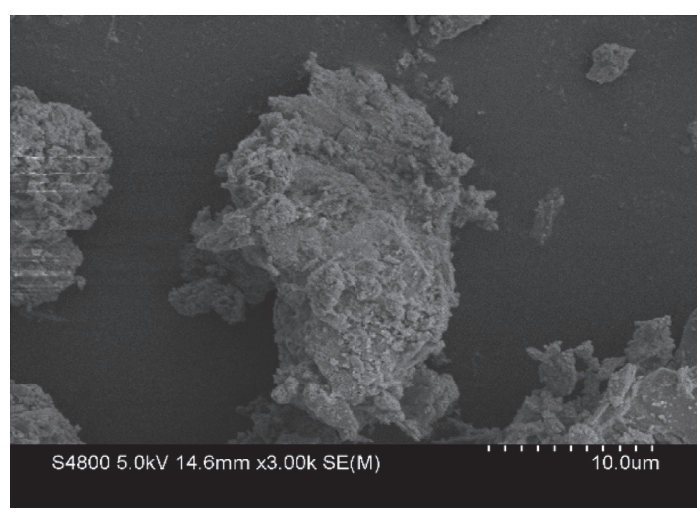

(a)

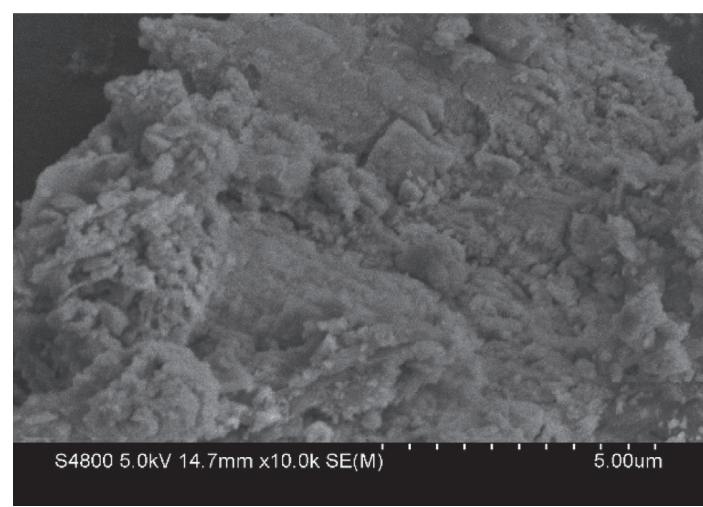

(c)

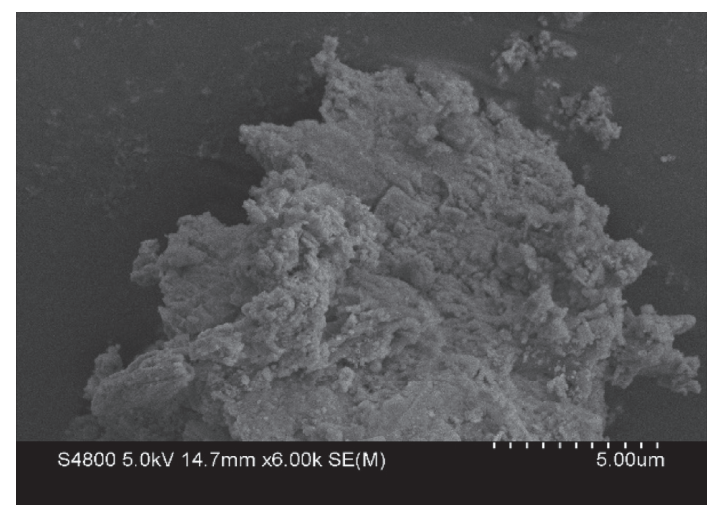

(b)

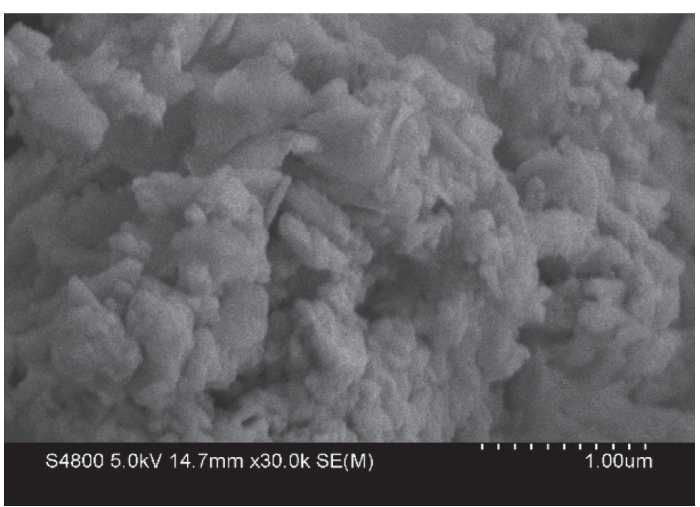

(d)

FIgURE 2: SEM images of studied materials. (a) 3000 times. (b) 6000 times. (c) 10000 times. (d) 30000 times.

completion of the unloading cycle was recorded as $\varepsilon_{r}$. The adjustment strain at the end of the unloading was calculated using the equation $\varepsilon_{10}=\varepsilon_{r}-\varepsilon_{0}$. The recovery rate $R$ and the irrecoverable creep flexibility $\mathrm{J}_{\mathrm{nr}}$ at $0.1 \mathrm{kPa}$ were obtained by averaging the data after 10 cycles at $0.1 \mathrm{kPa}$. The recovery rate $R$ and irrecoverable creep flexibility $\mathrm{J}_{\mathrm{nr}}$ at $3.2 \mathrm{kPa}$ were obtained by averaging the 10 cycles of data at $3.2 \mathrm{kPa}$, and the calculation is shown in

$$
\begin{aligned}
R & =\frac{\varepsilon-\varepsilon_{10}}{\varepsilon_{10}}, \\
J_{n r} & =\frac{\varepsilon_{10}}{\delta} .
\end{aligned}
$$

3.6. Bending Beam Rheology (BBR). The test apparatus was TE-BBR-type low-temperature bending beam rheometer manufactured in the United States. Refer to JTG E20-2011 [35] for the asphalt bending creep stiffness test method. The test temperatures were $-12^{\circ} \mathrm{C}$ to $-24^{\circ} \mathrm{C}$. Record the load deformation data at $60 \mathrm{~s}$. The low-temperature performance of the waste raw oyster shell powder asphalt binder was evaluated based on the creep stiffness modulus $S$ and creep rate $m$.

\section{Results and Discussion}

The interaction forms between oyster shell powder and asphalt binder were analyzed, and the effects of oyster shell powder on the basic properties, high-temperature rheological properties, and low-temperature rheological properties of asphalt binder were discussed. Since research on bio-modified asphalt has focused on several aspects of plantbased modified, bio-oil modified and bio-shell modified [39]. The performance advantages of oyster shell powder asphalt binders were further clarified by comparing the differences in the effects of different bio-modified materials on asphalt performance.

4.1. Chemical Characterization. The FTIR test is used to characterize the interaction between different functional groups, or the molecules of a composite, or between the same molecules in a blended system [40].

From Figure 4, it can be observed that the spectra of all the samples, regardless of whether they included oyster shell powder, showed a strong peak from $2800 \mathrm{~cm}^{-1}$ to $3000 \mathrm{~cm}^{-1}$. The difference between saturated and undersaturated hydrocarbons is whether the stretching vibration is less than $3000 \mathrm{~cm}^{-1}$. Therefore, the peaks at 2920 and $2847 \mathrm{~cm}^{-1}$ are attributed to the stretching vibrations of the saturated hydrocarbon $\mathrm{CH}_{2}$ in the asphalt. The peak at the wave number of $1600 \mathrm{~cm}^{-1}$ is partly caused by the $C=C$ stretching (benzene ring skeleton vibration) and partly by the absorption of $C=O$ stretching, thus indicating the presence of aromatic compounds in the asphalt binder. The in-plane bending vibration absorption peaks at $1457 \mathrm{~cm}^{-1}$, and 


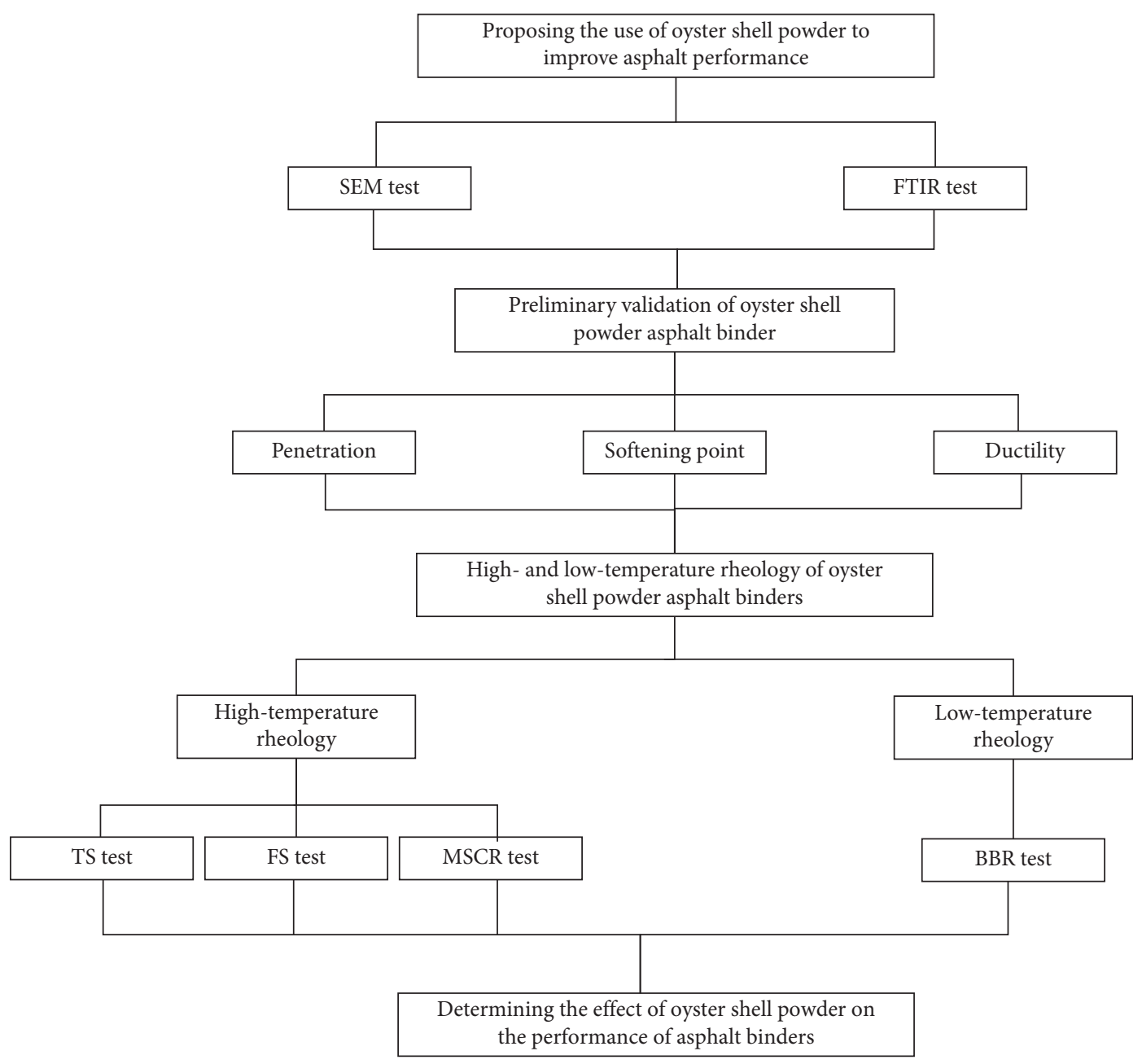

Figure 3: Research methodology flow chart.

$1373 \mathrm{~cm}^{-1}$ represents the $\mathrm{C}-\mathrm{H}$ ring stretching from aliphatic compounds. The four peaks at $864,812,746$, and $721 \mathrm{~cm}^{-1}$, located in the fingerprint area, are characteristic groups of a class of aromatic compounds caused by $\mathrm{C}-\mathrm{H}$ out-of-plane bending vibrations.

For a mixture of several substances, if there is excellent compatibility or chemical reaction between the different substances, the spectrum of the mixture will produce large deviations, such as shifted absorption peak positions, new peaks, and asymmetric broadening of peaks. Comparing the spectra of the matrix asphalt and the asphalt mixture of waste oyster shell powder with different blends, it was found that the peak positions of the four sets of infrared spectra were basically the same, and no new peaks were generated, indicating that no new chemical groups were generated between the waste oyster shell powder and the asphalt, and it was a physically modified, mainly co-blended, system.

When bio-oil was used for modification, the bio-oil extracted from waste wood contained a large number of oxygen-containing functional groups, and alkanes would react chemically with oxygen, leading to easier aging of

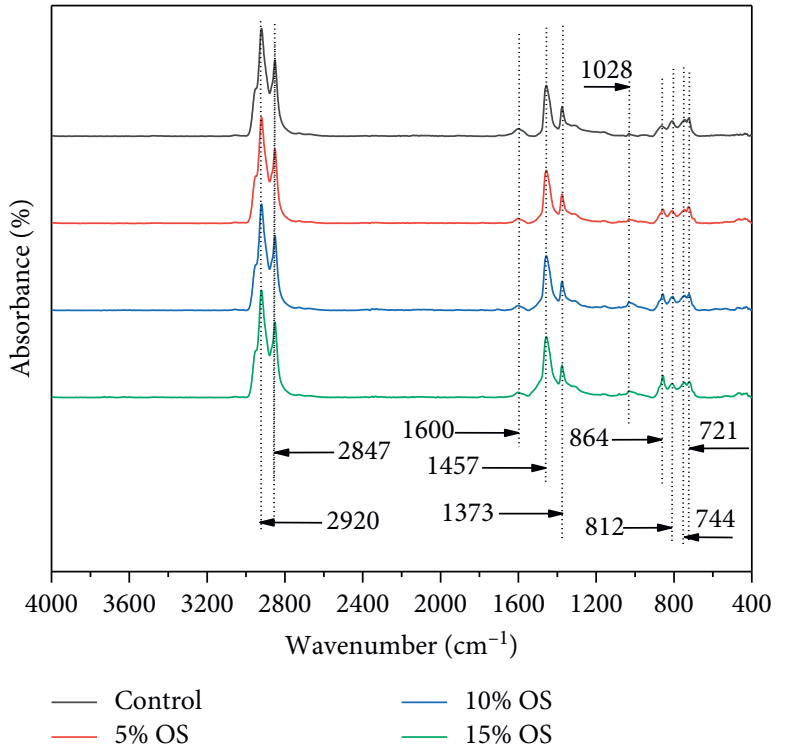

FIGURE 4: Fourier transform infrared spectrum of the studied materials. 
asphalt [41]. Bio-oil extracted from animal manure contains a large number of polar functional groups (amines, hydroxyl, sulfoxide, etc.) that when they associate with asphalt, they have a softening effect on asphalt [42]. When plantbased modification was used, the infrared spectra of asphalt binders from lignin fibers [31], corn stalks [43], rice straw stalks, and rapeseed [44] were essentially the same as the matrix asphalt with no chemical reaction. When biological shell was used for modification, crayfish shell powder [34], fish scale powder [45], and oyster shell powder had more similar properties and just physically mixed.

4.2. Conventional Performance. In road engineering materials, the three major indicators of asphalt testing are not only an essential part of the process but are also important technical indicators for classifying the viscous petroleum asphalt.

Penetration is one of the main indicators of asphalt and can indicate softness, consistency, and resistance to shear failure [46]. Penetration classification is also one of the most representative systems for evaluating pavement asphalts worldwide. The softening point, which indicates the transition of asphalt from the viscoplastic state into a viscous flow state at the critical temperature, is a conditional viscosity index. In general, the softening point is used initially to evaluate the high-temperature stability of asphalt [47]. The ductility characterizes the plastic deformation capacity of the asphalt material [48]. Studies have shown that the larger the ductility is, the larger the plastic deformation capacity of the asphalt, the better its crack resistance, and the less prone the pavement is to cracking. Figure 5 shows the conventional performance of the asphalt.

From Figure 5(a), it is found that the penetration of the needle decreases with the increase in waste oyster shell powder dosing, and the rate of decrease gradually declines with the increase in dosing. The penetration of the needle decreased by $21.01 \%, 25.23 \%$, and $26.88 \%$ compared with the matrix asphalt when the admixture amounts were $5 \%, 10 \%$, and $15 \%$, respectively.

When bio-oil was used in the preparation of asphalt binder, the penetration increased considerably and continued to increase with the amount of mixture. When plantbased modifier were used, the bio-asphalt prepared from sargassum substantially reduced the penetration of the asphalt binder, with a $15 \%$ reduction in the penetration of the asphalt binder from 5\% sargassum [40]. The degree of penetration decreased by $6 \%$ at $6 \%$ of corn stalk asphalt material [49]. The most significant decrease in the penetration of the asphalt binder was observed when the bio-shell was used for modification, and the penetration of $5 \%, 10 \%$, and $15 \%$ crayfish shell powder decreased by $49 \%, 52 \%$, and $56 \%$, respectively, compared to the matrix asphalt [34]. It shows that the penetration of the asphalt binder is closely related to the nature of the modified material, the bio-oil material is liquid, and the grease will reduce the friction between the probe and the asphalt, resulting in a significant increase in the penetration of the bio-oil-modified asphalt. When the plant-based material was used for modification, straw and corn stalk hardness will be low, but the fibers in the plant-based materials have a certain toughness and the fibers intertwine during the asphalt mixing process, which increase the hardness of the material. Oyster shells and crayfish shells are hard materials. When they are mixed with asphalt to increase the hardness of the bonding material, the penetration of the asphalt binder could be significantly reduced. The results showed that waste oyster shells could improve the hardness, consistency, and shear resistance of matrix asphalt.

Figure 5(b) shows that all three doping levels improved the softening point of the asphalt materials. The softening points of asphalt binders were increased by $3.7 \%, 6.7 \%$, and $9.8 \%$ compared to the neat asphalt when waste oyster shell powder was mixed at $5 \%, 10 \%$, and $15 \%$, respectively.

Bio-oil asphalt binder's softening point decreases with the increase of admixture. When the content of bio-oil admixture was $15 \%$, a significant decrease in softening point indicated that the high dose of bio-oil reduced the hightemperature performance of asphalt materials [50]. Plantbased-modified materials softening point of cornstalk asphalt binder increased with the increase of admixture [49]. The softening point of rapeseed asphalt binders decreased with the increase of admixture [44]. The softening points of crayfish shell powder and oyster shell powder asphalt binders all increased with the increasing amount of admixture. This may be due to the fact that bio-oil and rapeseed would absorb a lot of heat in the asphalt binder to reduce energy loss and soften the asphalt rapidly, thereby causing the softening point of the asphalt binder to decrease. Corn stalks, crayfish shells, and oyster shells have a higher energy loss during the heating process due to low heat absorption efficiency, resulting in a longer time required for the asphalt binder to soften and a higher softening point. The test results showed that the waste oyster shell powder could effectively increase the rutting resistance of asphalt at high temperature.

As shown in Figure 5(c), the ductility of asphalt decreased by 2, 4, and $9 \mathrm{~mm}$ with different amounts of waste oyster shell powder compared to the neat asphalt, with a decrease rate of $2.6 \%, 5.2 \%$, and $12 \%$. Through the analysis of the test results, it was revealed that the waste oyster shell powder hardened the asphalt material and made it more susceptible to damage and reduced plastic properties. This may be due to the fact that the discarded oyster shell powder particles impede the movement of asphalt macromolecules, thus reducing the ductility of the asphalt material, and the effect of this impediment increases with an increase in the shell powder particle content.

Bio-oil modifiers extracted from animal manure and waste wood could diffuse more rapidly in asphalt materials, and the ductility of asphalt binders increases with the increasing amount of admixture [41]. The $5^{\circ} \mathrm{C}$ ductility of rapeseed asphalt binders in plant-based-modified materials decreases with the increase of admixture, with a $30 \%$ decrease in ductility compared to the matrix asphalt at $4 \%$ admixture [44]. The ductility of cornstalk asphalt binder increases with the increase of admixture [49]. The ductility of oyster shell powder gradually decreases due to the increase 


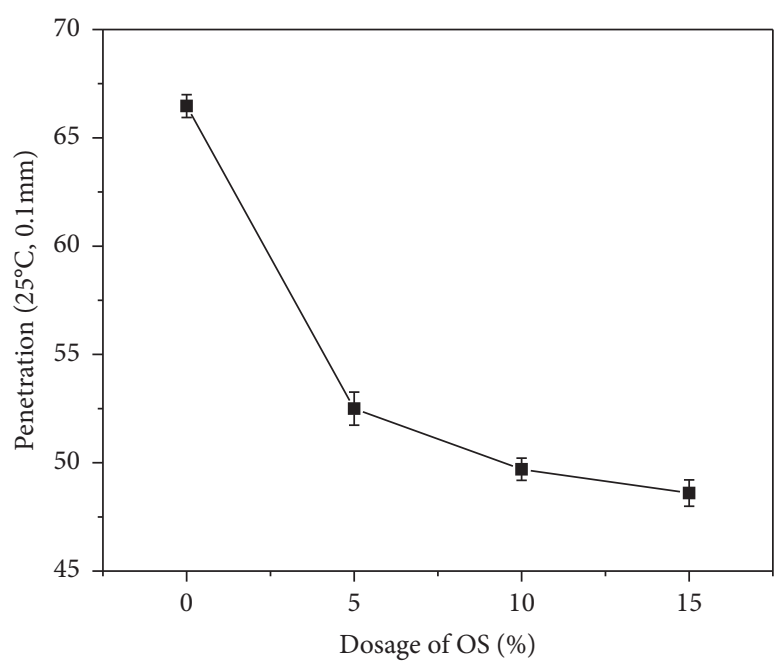

(a)

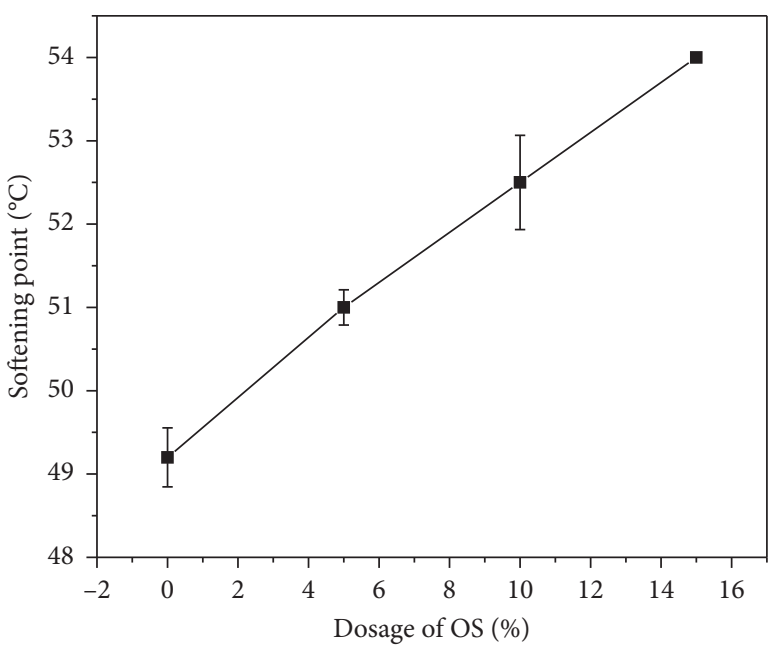

(b)

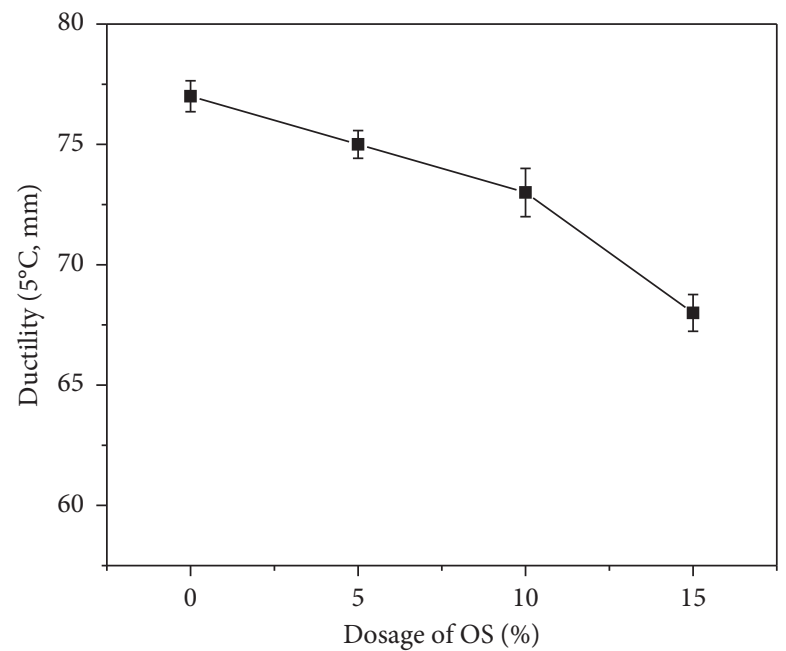

(c)

Figure 5: Conventional Performance of asphalt. (a) Penetration. (b) Softening point. (c) Ductility.

of the admixture. It showed that bio-oil decreased the stiffness of the asphalt binder and ensured sufficient light material in the asphalt binder under high-temperature conditions, which is equivalent to increasing the proportion of oil in the material, so the material has better ductility. Plant-based modified and bio-shell modified are physically modified, granular modified materials would make the internal stress of asphalt binder stronger. Asphalt in the tensile process creates a weak surface prone to fracture, thereby accelerating the damage. The fibrous modified material would improve the crack resistance of the material due to fiber winding. However, considering that many factors could affect the ductility, and the ductility test used external force to stretch the asphalt directly, the effect of waste oyster shell powder on the plastic deformation capacity of asphalt needs to be further studied.

4.3. Temperature Sweep. In the temperature sweep, the dynamic shear modulus $\left|\mathbf{G}^{*}\right|$ indicates the resistance to shear deformation of the asphalt binder [51]. The rutting factor $\left(\left|\mathbf{G}^{*}\right| / \sin \delta\right)$ reflects the resistance of the asphalt to permanent deformation. It can evaluate the resistance of the asphalt binder to rutting deformation [52]. The higher $\left(\left|\mathbf{G}^{*}\right| / \sin \delta\right)$ is, the lower the permanent deformation of the asphalt binder, the better the resistance to rutting.

The $\left|\mathbf{G}^{*}\right|, \delta$, and $\left(\left|\mathbf{G}^{*}\right| / \sin \delta\right)$ of the studied material by temperature sweep from $40^{\circ} \mathrm{C}$ to $70^{\circ} \mathrm{C}$ are shown in Figure 6 .

As shown in Figure 6, as the temperature increases, the $\left|\mathbf{G}^{*}\right|$ of the studied material decreases with a consistent trend for each doping amount. This is due to the major effect of the elastic component of the asphalt binder in reflecting its elastic properties at low temperatures. As the temperature increased, the asphalt binder gradually exhibited nonNewtonian viscous fluid properties. Therefore, the repeated shear deformation resistance of asphalt materials at low temperatures is larger and $\left|\mathbf{G}^{*}\right|$ becomes larger, and the repeated shear deformation resistance at high temperatures becomes smaller and $\left|\mathbf{G}^{*}\right|,\left|\mathrm{G}^{*}\right|$ becomes smaller. 


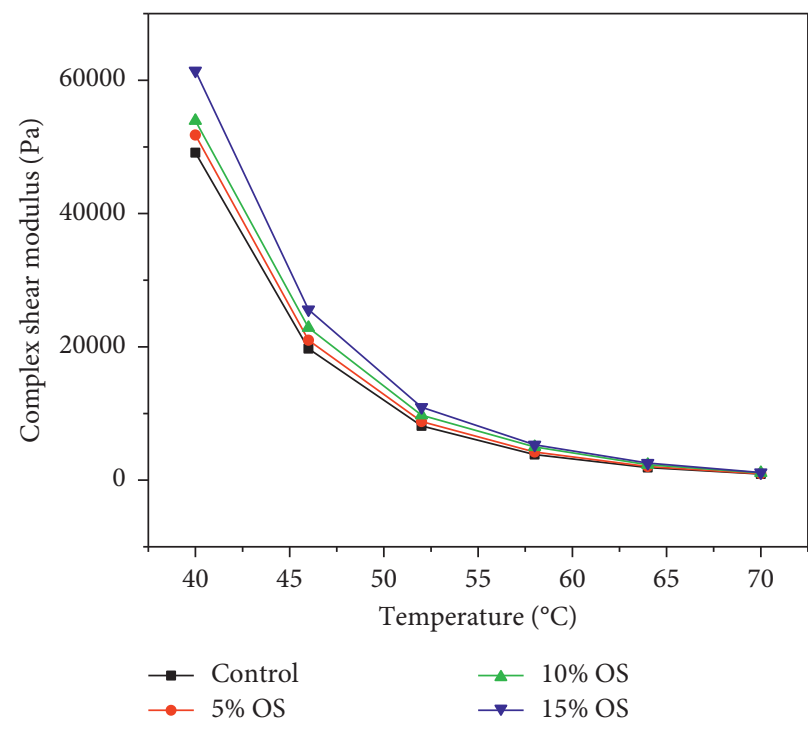

(a)

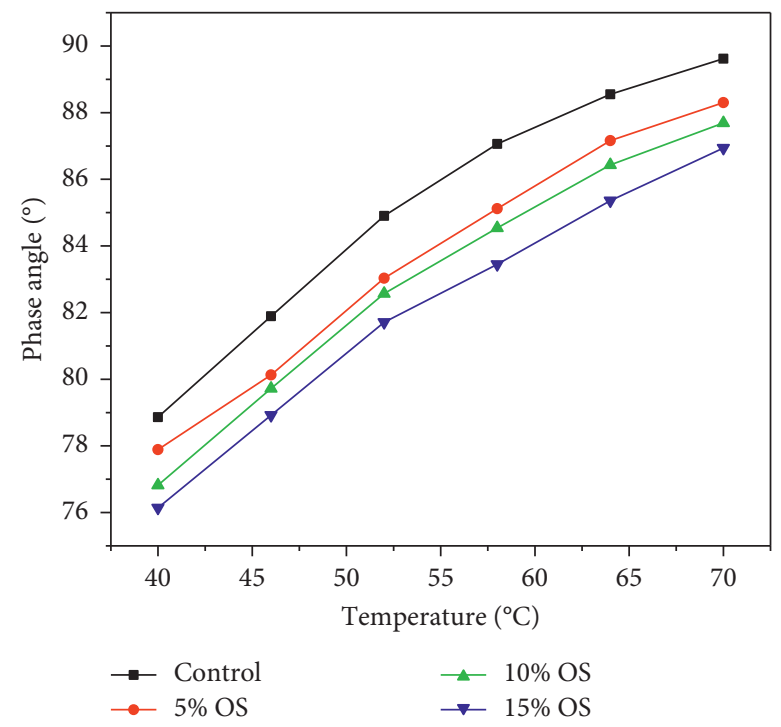

(b)

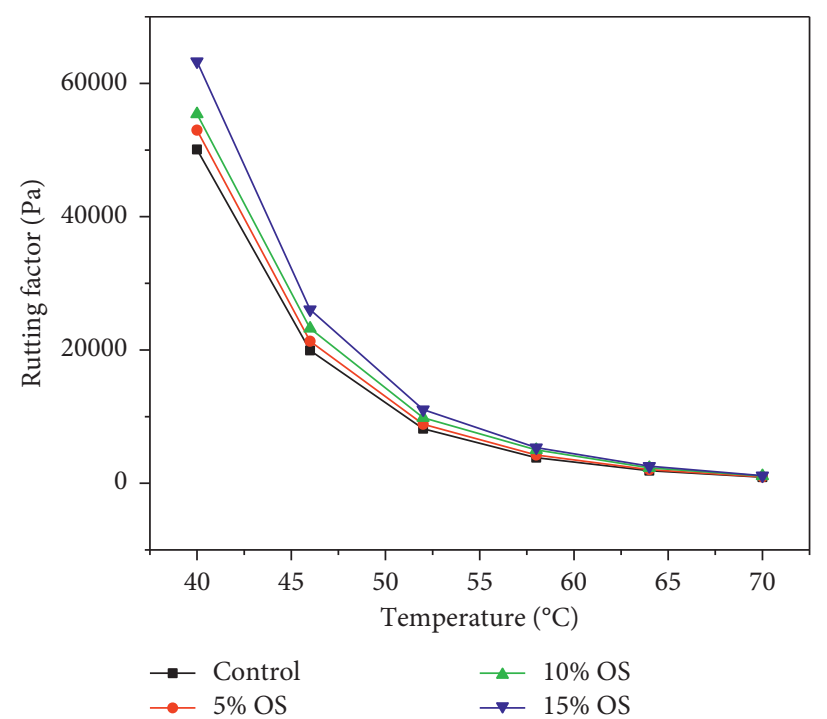

(c)

FIgURE 6: Temperature sweep. (a) $\left|\mathbf{G}^{*}\right|$ of the studied material during the temperature sweep. (b) $\delta$ of the studied material during the temperature sweep. (c) $\left(\left|\mathbf{G}^{*}\right| / \sin \delta\right)$ of the studied material during the temperature sweep.

At the same temperature with different amounts of asphalt binder, $\left|\mathbf{G}^{*}\right|$ increases with the amount of admixture. In the temperature range of $40^{\circ} \mathrm{C}$ to $70^{\circ} \mathrm{C}$, oyster shell powder asphalt binder compared to the base asphalt $\left|\mathbf{G}^{*}\right|$ is improved. The test results showed that the waste oyster shell powder could improve the permanent deformation resistance of asphalt, and the enhancement effect was most significant at $58^{\circ} \mathrm{C}$.

$\delta$ indicates the angle of strain lagging behind the stress when the asphalt material is subjected to shear loading. The lower the angle, the shorter the time required for the strain to react to the stress, indicating that the asphalt is more elastic, and the elastic recovery performance improves after the same deformation occurs. From Figure 7, it is seen that the $\delta$ of the asphalt binder increases with the temperature. This indicates that the elastic modulus $G^{\prime}$ percentage decreases and the loss modulus $\mathbf{G}^{\prime \prime}$ percentage increases with the increase in temperature, the asphalt changes from solid to liquid state, and the elastic recovery capacity gradually decreases. At the same temperature, the higher the amount of waste oyster shell powder, the smaller is the $\delta$ of the asphalt binder. In the temperature range of $40^{\circ} \mathrm{C}-70^{\circ} \mathrm{C}$, the $5 \%, 10 \%$, and $15 \%$ dose of oyster asphalt binder decreased $\delta$ compared to the base asphalt. Waste oyster shell powder can improve the rebound stability of asphalt at the same temperature, mainly because the interaction between the molecules of asphalt is modified by the waste oyster shell powder, which results in better elasticity than the matrix asphalt.

The deformation resistance of bituminous materials is affected by the combination of both $\left|\mathbf{G}^{*}\right|$ and $\delta$ of the asphalt. Thus, it is not rigorous to judge the rheological properties of 


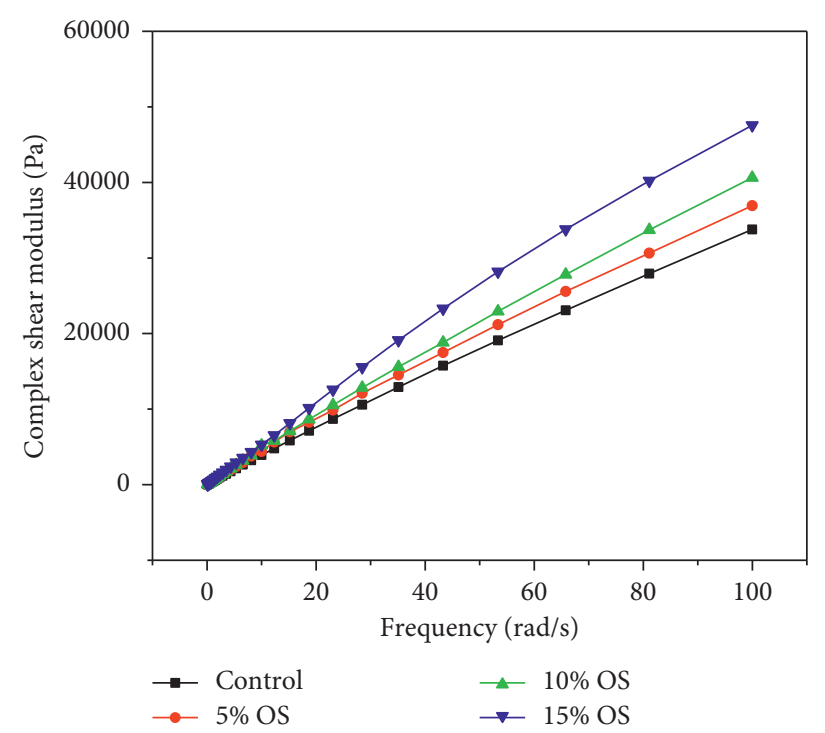

(a)

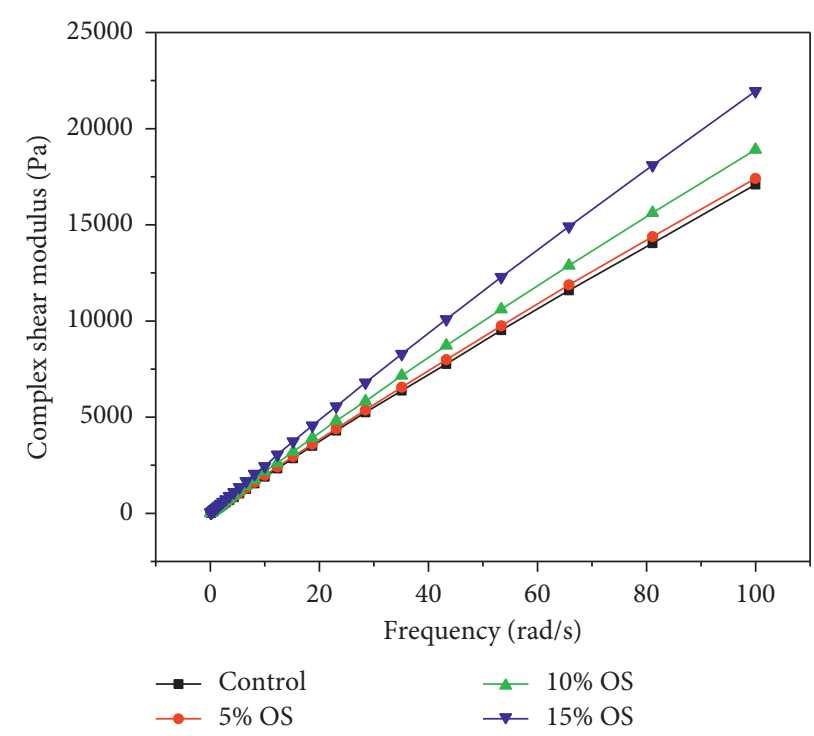

(b)

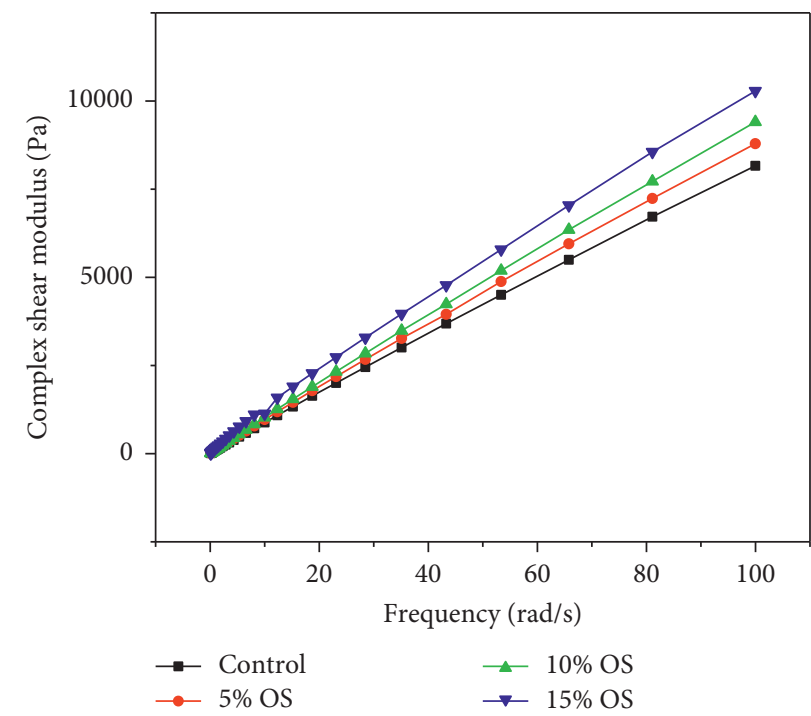

(c)

Figure 7: Complex shear modulus for various amounts of asphalt binders under fs. (a) $58^{\circ} \mathrm{C}$. (b) $64^{\circ} \mathrm{C}$. (c) $70^{\circ} \mathrm{C}$.

asphalt materials simply by comparing the magnitudes of $\left|\mathbf{G}^{*}\right|$ and $\delta$. The US SHPR specifies $\left(\left|\mathbf{G}^{*}\right| / \sin \delta\right)$ as an index to evaluate the high-temperature rheology of asphalt. The asphalt meets the temperature grading criteria of $\left(\left|\mathbf{G}^{*}\right| / \sin \delta\right)$ above $1.0 \mathrm{kPa}$. From Figure 8 , it can be seen that the $\left(\left|\mathbf{G}^{*}\right| / \sin \delta\right)$ of the asphalt binder decreases with increasing temperature, However, the trend of asphalt binder $\left(\left|\mathbf{G}^{*}\right| / \sin \delta\right)$ was not affected by the admixture of waste oyster shells. The $\left(\left|\mathbf{G}^{*}\right| / \sin \delta\right)$ of the asphalt binder at the same temperature increases with increasing amount of waste oyster shell powder. When the temperature is within $40^{\circ} \mathrm{C}$ $-70^{\circ} \mathrm{C}$, with $5 \%$ of waste oyster shell powder in the asphalt binder, $\left(\left|\mathbf{G}^{*}\right| / \sin \delta\right)$ increased by $5.76 \%, 6.92 \%, 8.38 \%$, $10.56 \%, 8.47 \%$, and $7.02 \%$, respectively, compared with the matrix asphalt; with $10 \%,\left(\left|\mathbf{G}^{*}\right| / \sin \delta\right)$ increased by $10.01 \%$, $15.53 \%, 18.71 \%, 27.67 \%, 20.94 \%$, and 19.11 , respectively; and with $15 \%,\left(\left|\mathbf{G}^{*}\right| / \sin \delta\right)$ increased by $23.81 \%, 26.38 \%, 29.25 \%$, $30.24 \%, 29.60 \%$, and $22.38 \%$, respectively. The $\left(\left|\mathbf{G}^{*}\right| / \sin \delta\right)$ of the $15 \%$ asphalt binder is still larger than $1.0 \mathrm{kPa}$, which meets the requirements of the specification. It was found that the waste oyster shell powder could improve the hightemperature performance of the asphalt binder and was most effective in improving the rutting resistance of the matrix asphalt at $58^{\circ} \mathrm{C}$.

Animal manure and plant-derived bio-oil soften the asphalt, resulting in a significant decrease in high-temperature viscosity [53]. The high-temperature stability of the material was reduced. When adding plant-based and bioshell-modified asphalt binders, due to the nature of the modifier itself and the properties of the physical mixture, asphalt binder hardness is significantly increased, $\left(\left|\mathbf{G}^{*}\right| / \sin \delta\right)$ decreased noticeably. The bio-shell-modified 


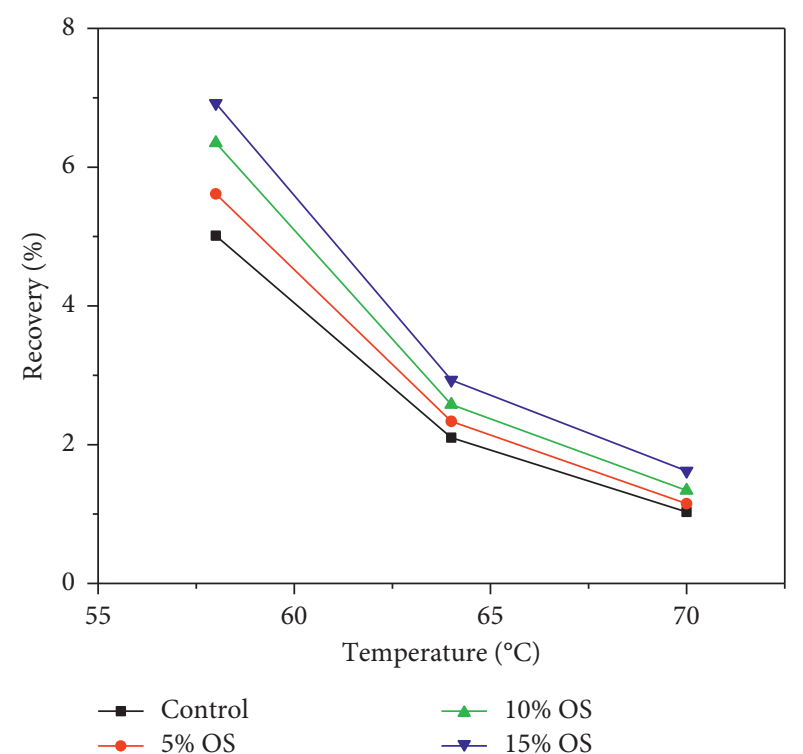

(a)

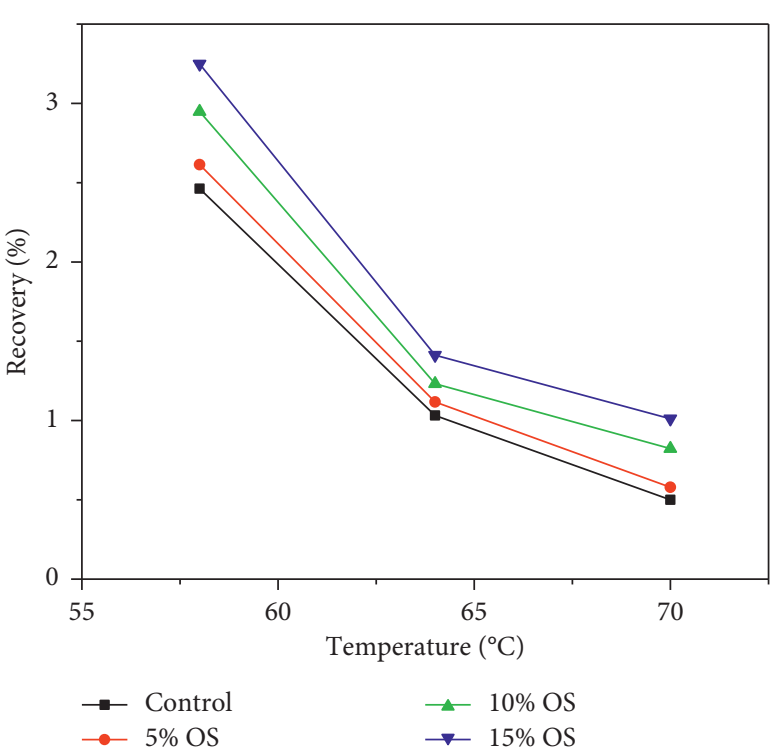

(b)

Figure 8: The average recovery rate of the studied materials. (a) $0.1 \mathrm{kPa}$. (b) $3.2 \mathrm{kPa}$.

material, due to its excellent high-temperature resistance and high hardness, has improved the high-temperature stability of the bio-shell-modified asphalt binder most significantly. Oyster shell powder was less used and the material is inexpensive, making it an ideal low-cost bio-modifier for improving the high-temperature stability of asphalt materials.

4.4. Frequency Sweep. FS simulates the duration of the load on the pavement, and high-frequency loading can simulate high-speed moving traffic, whereas low-frequency loading can simulate low-speed moving traffic [54]. Figure 7 shows the dynamic frequency sweep modulus variation curve with frequency for the studied material.

As can be seen in Figure 7, as the temperature increases, $\left|\mathbf{G}^{*}\right|$ decreases. This is because the high temperature promotes the movement of molecular chains within the asphalt material, which results in better fluidity. With increasing frequency, the asphalt binder $\left|\mathbf{G}^{*}\right|$ continues to increase. Since the high-frequency region is equivalent to the lowtemperature region, the fluidity of the asphalt binder decreased under low-temperature conditions, and the elastic content increased; thus, there was a higher modulus in the high-frequency region. The softer nature of the bio-oil asphalt binder results in a lower $\left|\mathbf{G}^{*}\right|$ for the high-temperature frequency sweep of the material than the control asphalt, and the higher the bio-oil admixture the smaller the $\left|\mathbf{G}^{*}\right|$ indicated that the bio-oil-modified material increases the shear deformation of the asphalt. The plant-based-modified asphalt binder $\left|\mathbf{G}^{*}\right|$ with the same amount of admixture is lower than the bio-shell-modified asphalt binder, This is due to the hardness of the bio-shell powder while the surface is rougher in the crushing process; therefore, it is more likely to improve the shear deformation resistance of the binder at high temperatures. Oyster shell powder in the range of $58^{\circ} \mathrm{C}$ $-70^{\circ} \mathrm{C}$; when the temperature is the same, the $\left|\mathrm{G}^{*}\right|$ of binders with waste oyster shell powder was higher than that of the neat asphalt, and at different temperatures, with $15 \%$ of waste oyster shell powder in the asphalt binder, $\left|\mathbf{G}^{*}\right|$ had a faster incremental rate, indicating that the asphalt binder shear deformation resistance was better. Therefore, the waste oyster shell powder can improve the material hardness and reduce the high-temperature shear deformation.

4.5. Multiple Stress Creep Recovery. Through the MSCR test of the asphalt binder, the corresponding relationship between the test time and creep cumulative strain of the matrix asphalt and oyster shell powder asphalt binder was obtained [55]. The calculation of $R$ and $\mathrm{J}_{\mathrm{nr}}$ of the studied materials showed that $\mathrm{J}_{\mathrm{nr}}$ can reflect the nonlinear rheological effects of asphalt under higher stresses and correlates well with the rutting resistance of the asphalt mixes. $R$ and $\mathrm{J}_{\mathrm{nr}}$ are shown in Figures 8 and 9 , respectively.

From Figure 8, it is found that the higher the temperature is, the lower the $R_{0.1}$ and $R_{3.2}$ of the asphalt binder at different temperatures, indicating that high temperatures reduce the elastic component of the asphalt binder and decrease the deformation recovery capacity. At the same temperature, the $R$ of the studied material ground increases with the increase of waste oyster shell powder.

From Figure 9, it was found that the $\mathrm{J}_{\mathrm{nr} 0.1}$ and $\mathrm{J}_{\mathrm{nr} 3.2}$ of the asphalt binder decreased with the increase of oyster shell admixture at the same temperature, indicating that the resistance to permanent deformation of the material increased and the high-temperature performance was improved.

The majority of bio-oil asphalt binders exhibited higher $\mathrm{J}_{\mathrm{nr}}$ and $R$; this may be due to the fact that bio-oil decreases the softening point of the asphalt binder, the more viscous and less elastic the asphalt is at the same temperature, thus 


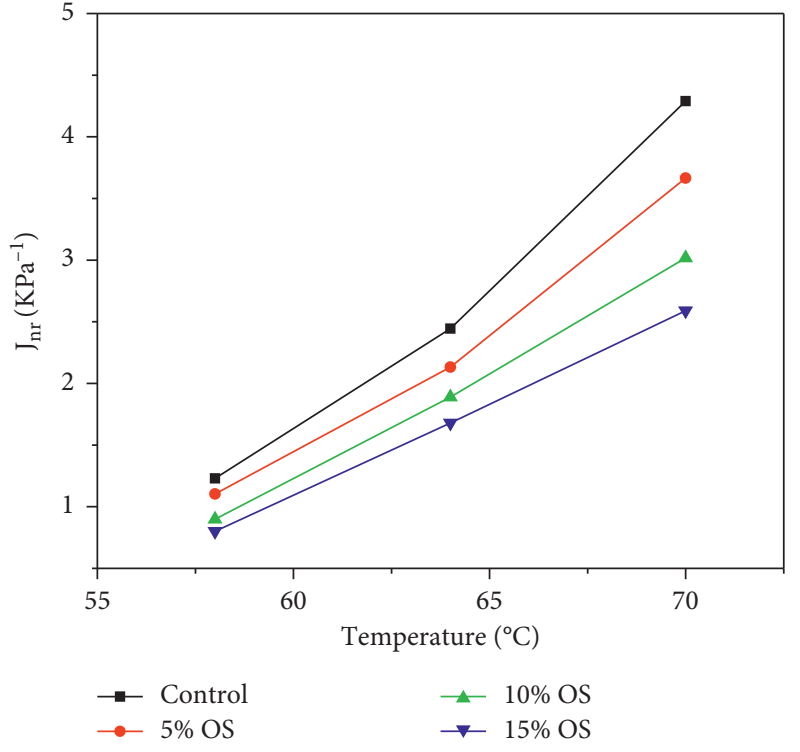

(a)

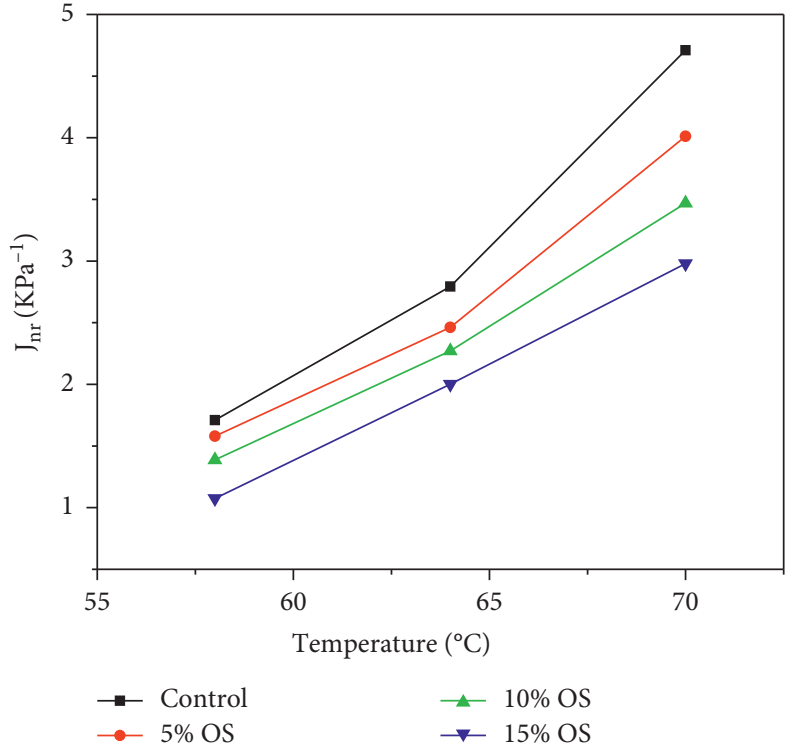

(b)

FIgURE 9: Average irrecoverable creep flexibility of studied materials. (a) $0.1 \mathrm{kPa}$. (b) $3.2 \mathrm{kPa}$.

resulting in a decrease in the high-temperature stability of the asphalt binder [50]. In the plant-based modifier, however, the tension of the fibrous material itself is equivalent to the increased elasticity of the asphalt due to the higher number of fibers inside the plant-based modifier. But compared with the bio-shell modifier, the rough and hard surface of the bio-shell will reduce the deformation of the material at the same load and improve the deformation resistance of the asphalt binder.

By comparing the studied materials at different temperatures, it was found that an increase in temperature would decrease $R_{0.1}, R_{3.2}, \mathrm{~J}_{\mathrm{nr} 0.1}$, and $\mathrm{J}_{\mathrm{nr} 3.2}$, respectively, while an increase in waste oyster shell powder admixture would decrease the difference of $R_{0.1}, R_{3.2}, \mathrm{~J}_{\mathrm{nr} 0.1}$, and $\mathrm{J}_{\mathrm{nr} 3.2}$ at different temperatures, indicating that waste oyster shell powder decreases the sensitivity of asphalt to temperature.

4.6. Bending Beam Rheology. The BBR test evaluates the creep degree of bitumen binders at lower temperature and constant load. S indicates the measure of asphalt binder resistance to constant load, reflecting the ability of the material to resist permanent deformation. $M$ indicates the change in stiffness of the asphalt binder under load, reflecting the time sensitivity of material stiffness and stress relaxation performance. The smaller the $S$ of the material, the better is its low-temperature flexibility, and the better the low-temperature rheological properties of the asphalt binder [56].

From Figures 10 and 11, it can be observed that the $S$ of the studied materials increases with decreasing temperature and $m$ decreases with decreasing temperature. It indicates that the low-temperature crack resistance of asphalt binder continues to decrease with the decrease of temperature, which is due to the fact that the asphalt binder will show a

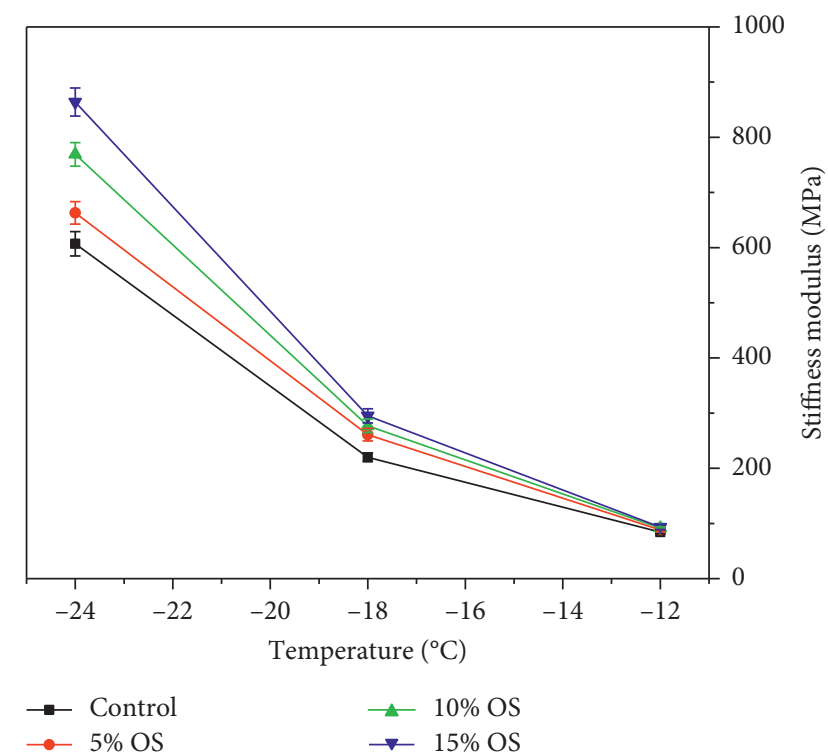

Figure 10: S-curve of asphalt binder for studied materials at low temperature.

glassy state and cannot move rapidly under low-temperature conditions. At the same temperature, the $\mathrm{S}$ and $m$ of the studied materials change less at $-12^{\circ} \mathrm{C}$ and $-18^{\circ} \mathrm{C}$, while $\mathrm{S}$ and $m$ change more at $-24^{\circ} \mathrm{C}$. This shows that the lowtemperature crack resistance of asphalt is less affected by the waste oyster shell powder within $-18^{\circ} \mathrm{C}$.

The $\mathrm{S}$ of asphalt binder with the addition of bio-oil decreased and $m$ increased, indicating that the cumulative strain of the material became smaller during the cooling process of asphalt binder, which improved the low-temperature crack resistance [57]. In contrast, the modified 


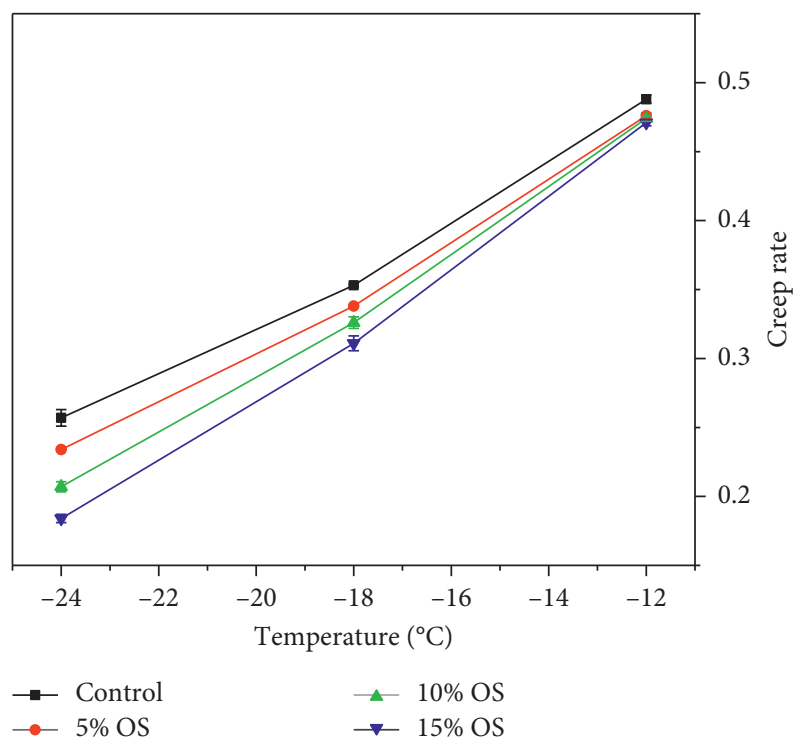

FIgURE 11: $m$-curve of asphalt binder for studied materials at low temperature.

materials such as corn stalk and fish scale powder among the plant-based and bio-shell modifiers all lead to an increase in $S$ and a decrease in $m$ of the asphalt binder $[42,46]$. This is because at the low-temperature conditions, the asphalt binder changes from viscous to plastic, and physical mixture of modified materials and asphalt bonding relies mainly on viscous components, resulting in asphalt binder being more prone to fracture, so the low-temperature cracking resistance of plant-based, bio-shell asphalt binder could be affected. Oyster shell powder has little effect on the lowtemperature cracking resistance of asphalt binder, which may be due to the fact that the surface of oyster shell powder is very rough after crushing, which can significantly increase the force between asphalt and shell powder to weaken the effect caused by the reduction of the bonding components. According to the 60s test in the SHPR specification, the asphalt material with $\mathrm{S}<300 \mathrm{MPa}$ and $\mathrm{m}>0.3$ meets the specification requirements. The figure shows that all the studied materials have a low temperature rating of $-18^{\circ} \mathrm{C}$.

\section{Conclusions and Recommendations}

Based on the test results, the following conclusions were drawn:

The oyster shell powder showed a rough, angular, and porous petal structure in the SEM test, which could improve the adsorption capacity of asphalt. The oyster shell powder asphalt binders did not produce new chemical groups, and the modified process is determined as physically modified.

Oyster shell powder asphalt binder was influenced by the amount of shell powder admixture, and the physical properties of the material changed with the increase of shell powder admixture. Harder oyster shell particles increased the hardness of the asphalt binder, resulting in a decrease in penetration and ductility. The lower heat absorption efficiency of oyster shells caused the softening point of the asphalt binder to rise.
High-temperature rheological evaluation of oyster shell powder asphalt binders showed that the stiffness of the materials was improved overall. With the increase of oyster shell admixture, the hard particles increased, $\delta$ and $\mathrm{J}_{\mathrm{nr}}$ decreased, but $\left(\left|\mathbf{G}^{*}\right| / \sin \delta\right)$ and $R$ have been improved. Therefore, it was believed that oyster shell powder would reduce the temperature sensitivity of asphalt binders and improve the rutting resistance and resistance to permanent deformation at high temperatures.

The BBR test found that the $S$ of oyster shell powder asphalt binder improved and $m$ decreased. It showed that oyster shell powder cannot improve the toughness and lowtemperature cracking resistance of asphalt binder. The materials are less affected within $-18^{\circ} \mathrm{C}$, and the low-temperature stability was significantly reduced at $-24^{\circ} \mathrm{C}$. The effect of extremely low temperatures on performance should be considered during application.

In summary, oyster shell powder can be used to improve the high-temperature stability and creep resistance properties of asphalt materials, promote the application of domestic waste in road engineering, and improve the environmental protection and sustainable development of road engineering.

\section{Data Availability}

The data cannot be shared due to restrictions, e.g., privacy and regulation.

\section{Conflicts of Interest}

The authors declare that there are no conflicts of interest regarding the publication of this paper.

\section{Acknowledgments}

The authors would like to thank Chang'an University and Tianjin Institute of Transportation Science for their support in testing materials and instrumentation. This research was funded by Hunan Provincial Department of Transportation (Grant no. B202013).

\section{References}

[1] R. M. Galante, J. V. C. Vargas, W. Balmant et al., "Clean energy from municipal solid waste (MSW)," in Proceedings of the ASME 2019 13th International Conference on Energy Sustainability Collocated with the ASME 2019 Heat Transfer Summer Conference, Bellevue, Washington, USA, July 2019.

[2] I. Muhammad, "Production of hydrogen enriched syngas from municipal solid waste gasification with waste marble powder as a catalyst-ScienceDirect," International Journal of Hydrogen Energy, vol. 44, no. 16, pp. 8051-8061, 2019.

[3] V. M. Adamović, D. Z Antanasijević, A. R Ćosović, M. Đ Ristić, and V. V Pocajt, “An artificial neural network approach for the estimation of the primary production of energy from municipal solid waste and its application to the Balkan countries," Waste Management (New York, N.Y.), vol. 78, pp. 955-968, 2018.

[4] S. Panigrahi and B. K. Dubey, "A critical review on operating parameters and strategies to improve the biogas yield from 
anaerobic digestion of organic fraction of municipal solid waste," Renewable Energy, vol. 143, pp. 779-797, 2019.

[5] S. Dehkordi, "Investigation of biogas production potential from mechanical separated municipal solid waste as an approach for developing countries (case study: isfahan-Iran)," Renewable and Sustainable Energy Reviews, vol. 119, 2020.

[6] X. Shi, G. Zheng, Z. Shao et al., "Effect of source-classified and mixed collection from residential household waste bins on the emission characteristics of volatile organic compounds," Science of The Total Environment, vol. 707, 2020.

[7] D. Lin, M. Sun, K. Zhang et al., "Analysis on the development situation of oyster industry in Fujian Province," China Fisheries, vol. 520, no. 3, pp. 62-66, 2019.

[8] H. Zen and C. Chen, "The design of the question of the Danish oyster crisis," Teaching Reference of Middle School Geography, vol. 19, pp. 62-63, 2017.

[9] C. Sasaki, S. Tamura, R. Tohse et al., "Isolation and identification of an angiotensin I-converting enzyme inhibitory peptide from pearl oyster (Pinctada fucata) shell protein hydrolysate," Process Biochemistry, vol. 77, pp. 137-142, 2019.

[10] M. A. Khirul, B. G. Kim, D. Cho et al., "Effect of oyster shell powder on nitrogen releases from contaminated marine sediment," Environmental Engineering Research, vol. 25, no. 2, 2019.

[11] M. Yamada, T. Tatsuno, H. Sano, and K. Tanabe, “A study on stabilization effect of the acid sulfate soil by using crushed oyster shell," Journal of the Society of Materials Science, Japan, vol. 54, no. 11, pp. 1117-1122, 2005.

[12] C. V. Schmidt, K. Olsen, and O. G. Mouritsen, "Umami synergy as the scientific principle behind taste-pairing champagne and oysters," Scientific Reports, vol. 10, 2020.

[13] P. S. O. D. Silva, E. D. O. ASena, M. I. S. Gonzaga et al., "Calcium carbonate particle films and water regimes affect the acclimatization, ecophysiology and reproduction of tomato," Environmental and Experimental Botany, vol. 165, pp. 19-29, 2019.

[14] China Statistics Press, National Bureau of Statistics of the People's Republic of China, China Statistical Yearbook 2018, Beijing, China, 2010.

[15] L. Hai-Yan, Y. Q. Tan, L. Zhang et al., "Bio-filler from waste shellfish shell: preparation, characterization, and its effect on the mechanical properties on polypropylene composites," Journal of Hazardous Materials, vol. 217, 2012.

[16] S. Das, S.-H. Lee, P. Kumar, K.-H. Kim, S. S. Lee, and S. S. Bhattacharya, "Solid waste management: scope and the challenge of sustainability," Journal of Cleaner Production, vol. 228, pp. 658-678, 2019.

[17] Y. Dai, X. Wang, W. Ye et al., "Study on resource utilization of mollusk shell waste," Resource Development \& Market, vol. 33, no. 2, pp. 203-208, 2017.

[18] G.-L. Yoon, B.-T. Kim, B.-O. Kim, and S.-H. Han, "Chemicalmechanical characteristics of crushed oyster-shell," Waste Management, vol. 23, no. 9, pp. 825-834, 2003.

[19] B. Ramakrishna and A. Sateesh, "Exploratory study on the use of cockle shell as partial Coarse \& Fine aggregate replacement in concrete," International Research Journal of Engineering and Technology (IRJET), vol. 3, pp. 2347-2349, 2016.

[20] B. Safi, M. Saidi, A. Bellal, A. Mechekak, and K. Toumi, "The use of seashells as a fine aggregate (by sand substitution) in self-compacting mortar (SCM)," Construction and Building Materials, vol. 78, pp. 430-438, 2015.

[21] S. Duan, Y. Muhammad, J. Li et al., "Enhancing effect of microalgae biodiesel incorporation on the performance of crumb Rubber/SBS modified asphalt," Journal of Cleaner Production, vol. 237, 2019.

[22] Y. Li, S. Wu, and S. Amirkhanian, "Investigation of the graphene oxide and asphalt interaction and its effect on asphalt pavement performance," Construction and Building Materials, vol. 165, pp. 572-584, 2018.

[23] L. A. B. Jing, L. Z. A. Feng, L. C. Yu et al., "Preparation and properties of soybean bio-asphalt/SBS modified petroleum asphalt," Construction and Building Materials, vol. 201, pp. 268-277, 2019.

[24] K. Yan, M. Zhang, L. You et al., "Performance and optimization of castor beans-based bio-asphalt and European rockasphalt modified asphalt binder," Construction and Building Materials, vol. 240, 2020.

[25] R. Zhang, H. Wang, Z. You, X. Jiang, and X. Yang, "Optimization of bio-asphalt using bio-oil and distilled water," Journal of Cleaner Production, vol. 165, no. 1, pp. 281-289, 2017.

[26] Y. Yi, Y. Huang, D. Feng et al., "Research status and application prospect of road biomass materials," Journal of China \& Foreign Highway, vol. 36, no. 1, pp. 221-228, 2016.

[27] S. Liu, H. Meng, Y. Xu et al., "Evaluation of rheological characteristics of asphalt modified with waste engine oil (WEO)," Petroleum Science \& Technology, vol. 36, pp. 1-6, 2018.

[28] E. H. Fini, "Source dependency of rheological and surface characteristics of bio-modified asphalts," Road Materials \& Pavement Design An International Journal, vol. 18, no. 2, pp. 408-424, 2017.

[29] H. D. Brian and OldhamBehzad, "Evaluation of low temperature viscoelastic properties and fracture behavior of bioasphalt mixtures," International Journal of Pavement Engineering, vol. 19, no. 4, pp. 362-369, 2018.

[30] J. Mills-Beale, Z. You, E. Fini et al., "Aging influence on rheology properties of petroleum-based asphalt modified with biobinder," Journal of Materials in Civil Engineering, vol. 26, no. 2, pp. 358-366, 2014.

[31] Y. Zhang, X. Wang, G. Ji et al., "Mechanical performance characterization of lignin-modified asphalt mixture," Applied Sciences, vol. 10, 2020.

[32] Y. Lei, H. Wang, X. Chen et al., "Shear property, high-temperature rheological performance and low-temperature flexibility of asphalt mastics modified with bio-oil," Construction and Building Materials, vol. 174, pp. 30-37, 2018.

[33] B. Sun and X. Zhou, "Diffusion and rheological properties of asphalt modified by bio-oil regenerant derived from waste wood," Journal of Materials in Civil Engineering, vol. 30, Article ID 04017274, 2018.

[34] S. Lv, C. Xia, Q. Yang et al., "Improvements on high-temperature stability, rheology, and stiffness of asphalt binder modified with waste crayfish shell powder," Journal of Cleaner Production, vol. 264, 2020.

[35] JTG E20-2011, Test Specification for Asphalt and Asphalt Mixture of Highway Engineering.

[36] H. Tan, S. Hu, B. Liu et al., "Study on viscoelastic properties of rubber modified asphalt based on rheology," China Civil Engineering Journal, vol. 50, pp. 115-122, 2017.

[37] Y. Xu and Z. You, "High temperature performance evaluation of bio-oil modified asphalt binders using the DSR and MSCR tests," Construction and Building Materials, vol. 76, pp. 380387, 2015.

[38] AASHTO T. 350-19, Standard Method of Test for Multiple Stress Creep Recovery (MSCR) Test of Asphalt Binder Using a 
Dynamic Shear Rheometer (DSR), AASHTO, Washington, DC, USA, 2019.

[39] L. Ding, X. Wang, M. Zhang et al., "Morphology and properties changes of virgin and aged asphalt after fusion," Construction and Building Materials, vol. 291, 2021.

[40] J. L. Rivera-Armenta, B. Cruz, S. Zapien et al., "Investigation of the performance of asphalt binder modified by sargassum," Construction and Building Materials, vol. 271, 2020.

[41] R. Zhang, J. Ji, Z. You et al., "Modification mechanism of using waste wood-based bio-oil to modify petroleum asphalt," Journal of Materials in Civil Engineering, vol. 32, 2020.

[42] E. H. Fini, E. W. Kalberer, A. Shahbazi et al., "Chemical characterization of biobinder from swine manure: sustainable modifier for asphalt binder," Journal of Materials in Civil Engineering, vol. 23, pp. 1506-1513, 2011.

[43] Z. X. Li, Y. C. Chen, J. B. Zhou, S. Sun, G. Y. Liu et al., "Analysis of road performance and mechanism of corn straw fiber asphalt mixes," Chinese Journal of Highways, vol. 32, pp. 47-58, 2019.

[44] M. Wróbel, A. Woszuk, M. Ratajczak et al., "Properties of reclaimed asphalt pavement mixture with organic rejuvenator," Construction and Building Materials, vol. 271, 2021.

[45] S. Lv, L. Hu, C. Xia et al., "Recycling fish scale powder in improving the performance of asphalt: a sustainable utilization of fish scale waste in asphalt," Journal of Cleaner Production, vol. 288, 2020.

[46] M. Chen, B. Leng, S. Wu et al., "Physical, chemical and rheological properties of waste edible vegetable oil rejuvenated asphalt binders," Construction and Building Materials, vol. 66, pp. 286-298, 2014.

[47] T. Ling, Y. Li, Q. Dong et al., "Influence of rubber particles on micro-surfacing performance and its noise-reduction effect," Journal of Traffic and Transportation Engineering, vol. 11, pp. 1-5, 2011.

[48] H. Liu, R. Chang, M. Zhang et al., "Study on low temperature performance of polyphosphoric acid modified asphalt and asphalt mixture," Journal of Hunan University (Natural Sciences), vol. 44, pp. 104-112, 2017.

[49] C. Hu, J. Feng, N. Zhou et al., "Hydrochar from corn stalk used as bio-asphalt modifier: high-temperature performance improvement and environmental impact," Environmental Research, vol. 193, 2020.

[50] Q. Zhang, P. W. Hao, and Z. Y. Bai, "Preparation and adhesion of waterborne epoxy modified emulsified asphalt," Highway Traffic Science and Technology, vol. 32, no. 9, pp. 9-14, 2015.

[51] M. Hu, D. Sun, Y. Zhang et al., "Evaluation of weathering aging on resistance of high viscosity modified asphalt to permanent deformation and fatigue damage," Construction and Building Materials, vol. 264, 2020.

[52] X. Han, Z. Cao, R. Wang et al., "Effect of silane coupling agent modified zeolite warm mix additives on properties of asphalt," Construction and Building Materials, vol. 259, 2020.

[53] T. Lu, G. Sun, Q. Pang et al., "A review on the preparation of bioasphalt from different biomass sources and its properties," Petroleum Asphalt, vol. 31, no. 3, pp. 60-66, 2017.

[54] S. Hu, H. Tan, R. Tan et al., "Compatibility test of rubber powder and matrix asphalt based on rheology," Acta Materiae Compositae Sinica, vol. 35, no. 12, pp. 259-271, 2018.

[55] C. Wang, H. Wang, L. Zhao et al., "Experimental study on rheological characteristics and performance of high modulus asphalt binder with different modifiers," Construction and Building Materials, vol. 155, pp. 26-36, 2017.
[56] L. Wang, M. Shan, C. Chang et al., "The macro-and mesocracking characteristics of warm mix crumb rubber asphalt mastics before and after aging," Construction and Building Materials, vol. 262, 2020.

[57] R. G. Duan, Research on the Modification Effect of Bio-Oil on Asphalt and its Mixes, Chang'an University, Xi'an, China, 2019. 